\title{
Surgical Treatment of Complicated Liver Echinococcosis - Our Experience with 184 Cases in 10 Years
}

\author{
Sorin Berbece ${ }^{1}$, Cristian Blajut ${ }^{2}$, Silviu Ciurea ${ }^{2}$, Victor Tomulescu², Irinel Popescu ${ }^{2}$
}

"University „Dunarea de Jos”, Faculty of Medicine and Pharmacy, Galati, Romania ${ }^{2}$ Center of General Surgery and Liver Transplantation, Fundeni Clinical Institute, Bucharest, Romania

\author{
Corresponding author: \\ Sorin Berbece, MD \\ E-mail: sorin.berbece@gmail.com
}

\section{ABSTRACT}

Background: The aim of this study was to analyze the treatment of patients with complicated liver hydatid cysts.

Methods: The records of 184 patients who had undergone surgery for complicated liver hydatid cyst in our institution during 2005 and 2014 were reviewed retrospectively.

Results: Among all complications, the most common were intrabiliary rupture (140 patients) and suppuration of the cysts (27 patients). Eleven cases had a combination of two complications. Other complications were rupture in the thorax (4 cases), rupture in the peritoneum (7 patients) and vascular erosions ( 6 patients). Surgery was based on the nature of complications, number and sizes of hydatid cysts and patients general condition. The surgical treatment of choice was partial (peri) cystectomies and drainage of the residual cavity with suture of the biliary fistula. In cases with complications such as suppuration, remaining bile fistulas, large cyst cavities or extrahepatic location, external drainage of the common bile duct (CBD)was mandatory. Post-operative complications occurred in 45 patients (24.4\%). Postoperative mortality was $1 \%$ (two patients). Conclusion: Appropriate investigation and well planned surgical techniques may improve the outcome of complicated liver echinococcosis. These data suggest that cyst diameter is an independent factor that is associated with a high risk of biliary-cyst communication in clinically asymptomatic patients. Preoperative endoscopic retrograde cholangiopancreatography (ERCP) should be performed in these asymptomatic patients to reduce the incidence of postoperative complications.

Key words: liver hydatid cyst, complications, outcomes

\section{INTRODUCTION}

Echinococcosis is endemic in some cattle and sheep herding areas, such as Mediterranean countries. The liver is the most frequent site of involvement and is infested in $50 \%$ to $70 \%$ of patients. (1) Surgery is indicated for complications of hepatic hydatid disease (HHD) in symptomatic patients and for asymptomatic patients unresponsive to antihelminthic treatment. Unfortunately, an increase in 
the rate of surgical treatments for this disease has not led to improvements in outcome; indeed, the high rate of intra and post-operative complications is often due to diagnostic, decision-making and technical errors.

Although the disease may occur in all age groups, 50-55 \% of cases are found in the 20-40 year age group. Movchun et al. (2) reported that $53.7 \%$ of patients were aged $40-49$ years.

Echinococcosis affects the liver rather than other organs in $50-70 \%$ of cases (3-7). While surgery is recognized as the only satisfactory method of treatment for liver echinococcosis (LE), many controversial results have been reported but total excision of the cyst alone or with part of the liver appears to be the most effective (8-11). This method is not always feasible however, since it depends on the size and site of the cyst. Moreover, intraoperative blood loss and postoperative bile leakage from the resected area may occur. A conservative approach of evacuation of the cyst contents may lead to problems of a residual cavity with the subsequent complications of biliary fistula, cavity contamination and drainage of purulent material.

Various procedures have been developed to overcome these complications such as external or internal drainage following evacuations and capitonnage with or without omentoplasty.

In this study, surgical treatment methods of complicated LE were evaluated according to the nature of complications and the character, location and sizes of cysts cavities.

\section{MATERIALS AND METHODS}

The surgical treatment of 184 patients with complicated liver hydatid cyst (LHC) who underwent surgery in our clinic between 2005 and 2014 were analyzed. Patients with the complicated form of disease comprised $21.6 \%$ of the total number of patients (853) who underwent surgery for LHC during the study period. The distribution of study patients according to sex and age is shown in table 1.
As seen from the table, most patients were aged between 19-60 years, thus demonstrating the social implications of the problem.

Complicated LE was diagnosed on the basis of clinical, laboratory and imagistic evaluation. Laboratory results were mostly inconclusive although significant findings included leukocytosis (19.1\%), anemia (21.3\%) and eosinophilia (5.1\%). The leading diagnostic tools for detecting the number, size and location of cysts are ultrasonography and computer tomography (CT), which have been demonstrated as having $90-100 \%$ accuracy.

Echography was used in all 184 patients preoperatively and in $95 \%$ of cases allowed not only diagnosis of LHC but also correct evaluation of complications and observation and pathologic changes in the bile ducts. In the 150 patients on whom CT scan was used, it was possible to detect the size, number and compactness of all hydatid cysts and the condition of the intra- and extrahepatic bile ducts. In two patients ERCP was used and was useful in clearing the CBD in both cases.

All 184 patients underwent surgery, with preoperative treatment according to individual needs and based on examination results. Generally, prophylaxis of hepato-renal failure and septic complications was under taken. For prophylaxis of septic complications, the broad spectrum antibiotic of choice was more recently ceftriaxon, administered at a dosage of $1 \mathrm{gm}$ iv immediately prior to surgery and continued at a dosage of $2.0 \mathrm{gm}$ iv, 12 hourly, for three to four days postoperatively.

Patients' treatment was selected according to their condition and the characteristics of the cyst. The indications for surgery were complicated cysts and uncomplicated, large, peripherally located, hydatid cysts. Open and laparoscopic (10 cases out of 184) approach was used and the type of surgical procedure was determined by each individual surgeon. Except for the 20 patients treated by liver resection ( 5 patients) or total pericystectomy (15 patients), all cysts were handled by unroofing of the cyst by partial pericystec-

Table 1 - Distribution of patients by age and sex

\begin{tabular}{|c|c|c|c|c|c|c|c|c|c|c|}
\hline \multirow[t]{2}{*}{ Sex } & \multicolumn{10}{|c|}{ Age } \\
\hline & $<18$ & $19-30$ & $31-40$ & $41-50$ & $51-60$ & $61-70$ & $71-80$ & $>80$ & total & $\%$ \\
\hline female & 12 & 24 & 18 & 19 & 17 & 15 & 6 & 1 & 112 & 61,20 \\
\hline male & 9 & 17 & 16 & 9 & 10 & 8 & 3 & 0 & 72 & 38,80 \\
\hline total & 21 & 41 & 34 & 28 & 27 & 23 & 9 & 1 & 184 & 100 \\
\hline$\%$ & 11,48 & 21,86 & 18,58 & 15,30 & 14,75 & 12,57 & 4,92 & 0,55 & 100 & \\
\hline
\end{tabular}


tomy and cavity management.

After unroofing, the edges of the pericystium were sutured with interlocking absorbable sutures to avoid bile leakage and bleeding. Cavity management was done by external drainage, omentoplasty, or capitonnage.

Peroxide solution was used as the scolicidal agent. At the beginning of surgery, all the cysts were aspirated to shrink their volume and to decrease intracystic pressure. Then, peroxide solution was injected into the cyst cavity and 10 minutes later the cyst cavity was opened. If biliary leakage was detected, only primary sutures or primary sutures with cholecystectomy and $\mathrm{t}$-tube drainage were performed.

All patients received albendazole $(10 \mathrm{mg} / \mathrm{kg} / \mathrm{d})$ preoperatively and postoperatively.

All the collected data were analyzed using the Microsoft Excel (v. 2013).

\section{RESULTS}

The most frequent complications of LHC was cystperforation into the bile ducts (140 patients), and infection or abscess of the cysts (27 patients). (table 2)

Twentyone patients $(11.41 \%)$ had more than one complication, the most common being suppuration with perforation into the bile ducts. Moreover, twenty of the patients with bile duct complications also had mechanical jaundice with associated cholangitis in eleven of them.

Most hydatid cysts of the liver were located in the right lobe (110 patients, $59.78 \%$ ) but in 53 patients $(28.8 \%)$ they were found in the left lobe and in 21 cases (11.41\%) in both lobes.

The types of operation for liver hydatid cysts are shown in table 3. In 139 patients (75.54 \%) the most acceptable procedure was partial (peri) cystectomies and drainage of the residual cavity, done by an open approach in 135 patients and by laparoscopic approach in 4 patients.

The 4 cases with rupture in the thorax with/without bronchobiliary fistula as follows. A combined thoracic
Table 2 - Types of preoperative complications in 184 patients

\begin{tabular}{lcc}
\hline Only intrabiliary rupture & 121 & $65,76 \%$ \\
\hline Only infection/ abscess & 25 & $13,59 \%$ \\
\hline The rupture in the thorax & 4 & $2,17 \%$ \\
\hline The rupture in the peritoneum & 7 & $3,80 \%$ \\
Vascular erosions & 6 & $3,26 \%$ \\
Multiple (intrabiliary rupture and infection/abcess) & 21 & $11.41 \%$ \\
\hline
\end{tabular}

and abdominal approach was used in 2 cases. One case the interventions consisted of pulmonary resection, partial cystectomys and drainage of the residual cavity and CBD Kehr tube drainage, and in the other one we used first ERCP with CBD drainage, thoracic drainage, and liver resection. Thoracic approach with phrenotomy and removal of the hepatic hydatid cysts was used in one case. The fourth case was resolved by abdominal approach with complete pericystectomy, phrenotomy and thoracic drainage.

Thirty out of 184 (16.3\%) patients developed 46 different complications following surgery (table 4) and 27 of these were specifically related to the type of surgical intervention.

Ten patients required surgical treatment of complications. Repeat laparotomy was performed on six patients due to formation and suppuration of a residual cavity, on two patients due to subdiaphragmatic or sub hepatic abscess, the rest of this kind of complications were treated by percutaneous approach. In two patients surgery was indicated due to peritonitis.

A fatal outcome was recorded in two $(1.09 \%)$ cases, the causes of death being acute hepatorenal insufficiency with multiple system organ failure (one case) and hydatic membrane pulmonary embolism (one case).

\section{DISCUSSIONS}

Some authors have reported that complicated LHC are diagnosed preoperatively in $30.3-34.7 \%$ of patients (12-19), thus one third of patients are admitted at the stage of complication development.
Table 3 - Types of operations

\begin{tabular}{|c|c|c|c|c|c|c|}
\hline Radical surgery & Open & $\%$ & Laparo & $\%$ & Total & $\%$ \\
\hline - Liver resections & 4 & 2,17 & 1 & 0,54 & 5 & 2,72 \\
\hline - Total (peri)cystectomy & 12 & 6,52 & 3 & 1,63 & 15 & 8,15 \\
\hline \multicolumn{7}{|l|}{ Conservative } \\
\hline $\begin{array}{l}\text { - Partial (peri)cystectomies } \\
\text { and drainage of the residual cavity }\end{array}$ & 135 & 73,37 & 4 & 2,17 & 139 & 75,54 \\
\hline - Partial (peri)cystectomies and omentoplasty & 23 & 12,50 & 2 & 1,09 & 25 & 13,59 \\
\hline Total $^{-}$ & $174^{-}$ & 94,57 & $10^{\circ}$ & 5,43 & 184 & $100^{-}$ \\
\hline
\end{tabular}


Table 4 - Complications after surgery for complicated LHC

\begin{tabular}{|c|c|c|c|}
\hline Complications & $\begin{array}{l}\text { Number } \\
\text { of cases }\end{array}$ & $\begin{array}{l}\% \text { of total number } \\
\text { complications }\end{array}$ & $\begin{array}{l}\% \text { of total number } \\
\text { of patients }\end{array}$ \\
\hline Suppuration of residual cavity & 14 & 30,43 & 7,61 \\
\hline External purulent fistula & 2 & 4,35 & 1,09 \\
\hline Hemorrhage in residual cavity & 4 & 8,70 & 2,17 \\
\hline Subdiaphragmatic and subhepatic abscesses & 4 & 8,70 & 2,17 \\
\hline Hydatic membrane pulmonary embolism (Fig. 1 ) & 1 & 2,17 & 0,54 \\
\hline Peritonitis & 2 & 4,35 & 1,09 \\
\hline \multicolumn{4}{|l|}{ Non-specific complications } \\
\hline Suppuration of wound & 10 & 21,74 & 5,43 \\
\hline Pneumonia & 3 & 6,52 & 1,63 \\
\hline Pleuritis & 2 & 4,35 & 1,09 \\
\hline Hepato-renal failure & 1 & 2,17 & 0,54 \\
\hline Illeus & 3 & 6,52 & 1,63 \\
\hline Total & 46 & & 25,00 \\
\hline
\end{tabular}

Suppuration is the most frequent complication of LHC (12-14). In the present study, cyst suppuration was less common than perforation into bile ducts ( $13.59 \%$ and $65.76 \%$ respectively). The first signs and symptoms of the disease (pyrexia, chills, sepsis and increased pain) may occur with the development of acute cyst infection.

In a large size residual cavity, with a central location and location of the cyst in projection of frank vessels, partial closure, with or without omentoplasty was used. Removal of the tube should only be undertaken under echography guidance after liquidation of the content and in the absence of a residual cavity.

The less radical procedure of partial (peri) cystectomies with external drainage but without narrowing or liquidation of the residual cavity was used in 103 patients in this study. Indications for the use of this method include cyst suppuration, unusual location (eg subdiaphragmal, intrahepatic) poor condition of the patient and need for rapid completion of operation.

Regional resection of the liver was performed in $2.72 \%$ of patients with regional location of cyst and cyst pedicle.

Rupture of hydatid cyst into the bile ducts and formation of cystobiliary fistulas occur in $4.5 \% 55 \%$ of patients with LHC (12-19). According to Harris (20), $90 \%$ of all cysts eventually affect the bile ducts. The present authors concur with the views of Movchun (2) who mark out intrahepatic (formation of internal fistula between cyst cavity and bile ducts) and extrahepatic (real rupture of parasite's elements into bile ducts) forms of disease.

Intraoperative diagnosis of cyst-biliary communication can be difficult and accurate preoperative determination of the presence of the fistula, its dimensions, and localization is essential for an optimal surgical

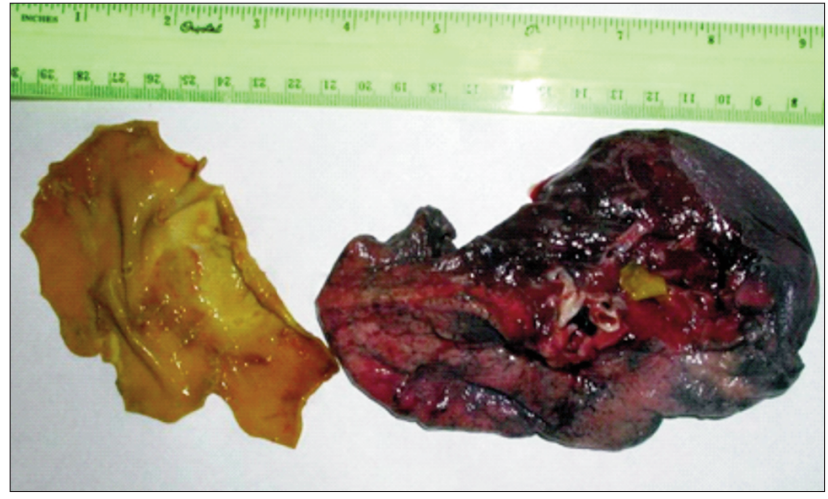

Figure 1 - Hydatic membrane pulmonary embolism

procedure. In addition, preoperative determination of a possible fistula could help in selecting the best therapeutic approach. (17)

ERCP is reported to be an effective alternative to surgical treatment of biliary fistula. $(1,18,19)$ ERCP is also a valuable method for detecting and treating postoperative complications involving the biliary tree after surgical intervention in patients with hepatic echinococcal disease. (19) Dumas et al suggested that ERCP before surgery is beneficial in patients who had symptoms referable to the biliopancreatic system. The incidence of postoperative fistulas was shown to decrease significantly after the introduction of selective preoperative $E R C P$, based on clinical and radiologic criteria. $(21,22)$ Preoperative routine use of ERCP may be useful, but there are no published data to support the routine use of ERCP in the preoperative assessment of patients with hydatid disease without biliary complications, although a single study suggested that prior endoscopic sphincterotomy minimizes the frequency of fistula formation after surgery. (23) 


\section{CONCLUSION}

In conclusion, surgical treatment of complicated liver echinococcosis may be improved with early diagnosis, the use of modern instrumental methods of investigation, well-planned surgical techniques and appropriate procedures based on correct evaluation of disease complication.

\section{REFERENCES}

1. Dumas R, Le Gall P, Hastier P, Buckley MJ, Conio M, Delmont JP. The role of endoscopic retrograde cholangiopancreatography in the management of hepatic hydatid disease. Endoscopy. 1999 Mar;31(3): 242-7.

2. Movchun AA, Koloss OE, Shatveryan GA et al. Mistakes and dangers of surgical treatment of liver echinococcosis. Chirurgia (Moscow) 1991;11:113-7.

3. Alwan MH. Internal drainage in the treatment of intrabiliary communication of hydatid cyst of the liver. Int Surg. 1982 Oct-Dec;67(4 Suppl): 456-8.

4. Elhamel A. Pericystectomy for the treatment of hepatic hydatid cysts. Surgery. 1990 Mar;107(3):316-20.

5. Morris D. Echinococcosis of the liver. Gut. 1994 Nov;35(11):1517-8.

6. Petrovsky BV, Milonov OB, Deenichin PN. Surgery of echinococcosis. Moscow "Medicina"; Sophia "Fizkulturaispor" 1985: p 215.

7. Vakhidov AV, II'khamov FA, Strusskiī LP, Azat'ian TS. Diagnosis and treatment of echinococcosis of the liver complicated by cysto-biliary fistula. Chirurgia (Moscow). 1998:(5):15-7. Russian

8. Alfieri S, Doglietto GB, Pacelli F, Costamagna G, Carriero C, Mutignani $\mathrm{M}$, et al. Radical surgery for liver hydatid disease: a study of 89 consecutive patients. Hepatogastroenterology. 1997 Mar-Apr;44(14): 496-500.

9. Belli L, Del Favero E, Marni A, Romani F. Resection versus pericystectomy in the treatment of hydatidosis of the liver. Am J Surg. 1983 Feb; 145(2):239-42.
10. Akinoğlu A, Bilgin I, Erkoçak EU. Surgical management of hydatid disease of the liver. Can J Surg. 1985 Mar;28(2):171-2, 174.

11. Cois A, lasiello G, Nardello O, Mattana A, Uccheddu A, Cagetti M. Human fibrin glue in the treatment of residual parenchymal surface after total pericystectomy for hepatic echinococcus. Ann Ital Chir. 1997 Sep-0ct; 68(5):701-6; discussion 706-9. Italian

12. Corneleac E, Cojocaru E, Crauciuc R, Manolescu E, Fischel J, Orhei 0 , et al. Hepato-cysto-cholecystostomy in voluminous central posthydatic residual cavities of the liver. Lyon Chir. 1966 Sep; 62(5):663-9. French

13. Jose Luis Barros Hydatid disease of the liver. Am J Surg. 1978 Apr;135(4):597-600

14. Karydakis P, Pierrakakis S, Economou N, Ninos A, Raitsiou B, Bobotis $E$, et al. Surgical treatment of hydatid cysts of the liver. J Chir (Paris). 1994 Aug-Sep;131(8-9):363-70. French

15. Chen WQ, Chai FL, Gu SN. Experience in the surgical treatment of hepatic hydatidosis. Zhonghua Wai Ke Za Zhi. 1994 Mar;32(3): 166-8. Chinese

16. Ferrari A, Rebecchi AM, Manenti F, D'Alimonte P. Hepatic echinococcosis. Minerva Gastroenterol Dietol. 1995 Dec;41(4):311-2. Italian

17. Ulualp KM, Aydemir I, Senturk H, Eyuboğlu E, Cebeci H, Unal G, et al. Management of intrabiliary rupture of hydatid cyst of the liver. World J Surg. 1995 Sep-0ct;19(5):720-4; discussion 728.

18. Tekant $Y$, Bilge 0 , Acarli K, Alper A, Emre A, Arioğul O. Endoscopic sphincterotomy in the treatment of postoperative biliary fistulas of hepatic hydatid disease. Surg Endosc. 1996 Sep;10(9):909-11.

19. Giouleme $\mathbf{0}$, Nikolaidis N, Zezos P, Budas K, Katsinelos P, Vasiliadis T, et al. Treatment of complications of hepatic hydatid disease by ERCP. Gastrointest Endosc. 2001 0ct:54(4):508-10.

20. Harris JD. Rupture of hydatid cyst of the liver into the biliary tracts. $\mathrm{Br}$ J Surg. 1965 Mar:52:210-4.

21. Galati G, Sterpetti AV, Caputo M, Adduci M, Lucandri G, Brozzetti S, et al. Endoscopic retrograde cholangiography for intrabiliary rupture of hydatid cyst. Am J Surg. 2006 Feb;191(2):206-10.

22. Iscan M, Düren M. Endoscopic sphincterotomy in the management of postoperative complications of hepatic hydatid disease. Endoscopy. 1991 Sep; 23(5):282-3.

23. Vagianos C, Polydorou A, Vagenas C, Dougenis D, Androulakis J. Combined endoscopic andsurgical treatment of complicated hepatic hydatidosis. Endoscopy. 1994 May;26(4):367. 